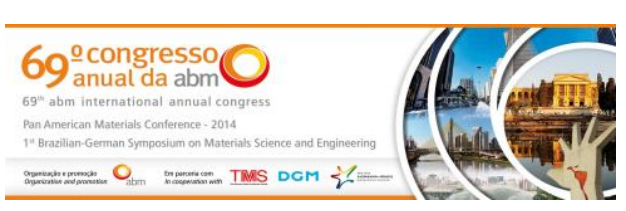

Tema: Produtos metálicos não-ferrosos

\title{
REMOÇÃO DE BORO DE SILÍCIO POR TRATAMENTO A PLASMA*
}

\author{
André Alexandrino Lotto ${ }^{1}$ \\ João Batista Ferreira Neto ${ }^{2}$
}

\section{Resumo}

A demanda global por energia renovável vem aumentando ao longo dos últimos anos. A energia solar é uma energia limpa e abundante, mas seu uso ainda é limitado por causa dos preços altos e baixa eficiência das células fotovoltaicas. $\mathrm{O}$ silício bruto, também chamado de silício de grau metalúrgico, tem sido alvo de muitos estudos visando sua purificação a um nível suficiente para aplicações de energia solar por processos mais baratos do que o processo convencional, chamado Processo Siemens. Neste trabalho, $3 \mathrm{~kg}$ de silício de grau metalúrgico foram fundidos por plasma térmico numa atmosfera de vapor de água, hidrogênio e argônio. O teor de boro foi reduzido de 10 ppm para 0,09 ppm em 18.000s (5 horas), mostrando que o processo poderia ser uma alternativa viável ao processo tradicional por via química.

Palavras-chave: Purificação de silício; Remoção de boro; Plasma.

\section{BORON REMOVAL FROM SILICON BY PLASMA TREATMENT}

\begin{abstract}
The global demand for renewable energy has been increasing over the past few years. Solar energy is a clean and abundant energy available, but their use is still limited because of high prices and low efficiency of photovoltaic cells. Bulk silicon, also called metallurgical grade silicon, has been the subject of many researches in its purification to a sufficient level for solar applications by cheaper processes than the conventional process, called Siemens Process. In this work, $3 \mathrm{~kg}$ of metallurgical grade silicon were melted by thermal plasma in an atmosphere of water vapor, hydrogen and argon. The boron content was reduced from $10 \mathrm{ppm}$ to $0.09 \mathrm{ppm}$ 18,000 s (5 hours), showing that the process could be a viable alternative to traditional expensive process by chemical route.
\end{abstract}

Keywords: Silicon purification; Boron removal; Plasma.

1 Engenheiro de Materiais, Pesquisador assistente, CTMM, Laboratório de Processos Metalúrgicos, Instituto de Pesquisas Tecnológicas do Estado de São Paulo (IPT), São Paulo, SP, Brasil.

2 Engenheiro Metalúrgico, Doutor, Pesquisador, CTMM, Laboratório de Processos Metalúrgicos, Instituto de Pesquisas Tecnológicas do Estado de São Paulo (IPT), São Paulo, SP, Brasil.

* Contribuição técnica ao 69 Congresso Anual da ABM - Internacional e ao 14ํㅡㄹ ENEMET - Encontro Nacional de Estudantes de Engenharia Metalúrgica, de Materiais e de Minas, 21 a 25 de julho de 2014, São Paulo, SP, Brasil. 


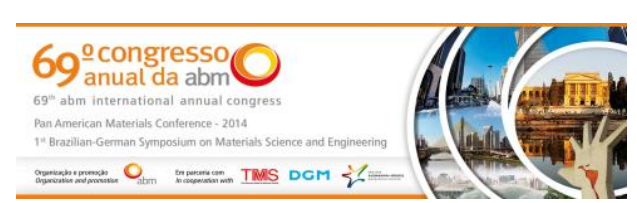

\section{INTRODUÇÃO}

O custo de um módulo solar pode variar em até $11 \%$ conforme as matérias-primas utilizadas, variando de silício grau eletrônico $(30 € / \mathrm{kg})$ a silício grau metalúrgico de alta pureza $(10 € / \mathrm{kg}$ ), para as tecnologias atuais e considerando-se que a eficiência seja mantida [1]. No passado a indústria fotovoltaica consumia silício grau eletrônico, caracterizado pela alta pureza e alto custo de produção. Atualmente, a indústria exige um silício específico para aplicações solares (silício grau solar) de menor pureza e menores custos de produção. Há duas frentes para produzir este tipo de silício: rotas químicas por clorosilanos e as rotas metalúrgicas, que têm um grande potencial para reduzir o custo, mas grandes incertezas sobre o impacto na eficiência das células produzidas com este silício [1].

O elevado custo do silício grau eletrônico está relacionado com o consumo de energia elétrica usada na sua produção. Abaixo estão listados consumos de energia típicos para a produção de silício de diferentes níveis de pureza [2]:

- silício grau eletrônico (processo Siemens) - pelo menos 40 kWh / kg

- silício grau solar (rota metalúrgica) - 15 a $30 \mathrm{kWh} / \mathrm{kg}$

- silício grau metalúrgico - 14 a $16 \mathrm{kWh} / \mathrm{kg}$

Nas rotas metalúrgicas que têm sido desenvolvidas por empresas e grupos de pesquisa ao redor do mundo, um processo chave é a solidificação direcional. No entanto, alguns elementos com maior coeficiente de partição, tais como fósforo e boro, não podem ser removidos por este processo. Outros processos têm sido desenvolvidos para a remoção destes elementos. No caso do boro, alguns autores vêm utilizando o tratamento a plasma com sucesso. Nakamura et al. [3] reduziram o teor de boro de 5 a $10 \mathrm{ppm}$ para < 0,1 ppm em massa. Outros autores [4] conseguiram remoção de boro de 24,8 ppm para 2,01 ppm em $10800 \mathrm{~s}$ (3 horas) a $1703 \mathrm{~K}\left(1430^{\circ} \mathrm{C}\right)$ sem a utilização do plasma, mas fundindo o silício em forno de indução sob atmosfera controlada contendo $\mathrm{Ar}, \mathrm{H}_{2}$ e $\mathrm{H}_{2} \mathrm{O}$. O princípio da purificação é a formação de compostos voláteis de boro com hidrogênio e oxigênio. Este trabalho se insere neste contexto.

\section{MATERIAIS E MÉTODOS}

$3 \mathrm{~kg}$ de silício grau metalúrgico foram fundidos por plasma térmico numa atmosfera de vapor de água, hidrogênio e argônio, em um cadinho de grafite por 18000 s (5 horas), com alteração na relação de gases após os primeiros $14400 \mathrm{~s}$ (4 horas). A área de superfície do banho exposta a atmosfera foi de $0,03 \mathrm{~m}^{2}$. A temperatura do banho foi medida por um pirômetro óptico, variando de $1923 \mathrm{~K}$ a $2023 \mathrm{~K}\left(1650{ }^{\circ} \mathrm{C} \mathrm{a}\right.$ $1750{ }^{\circ} \mathrm{C}$ ) na borda do líquido. As amostras foram colhidas ao longo do tempo e analisadas por espectrometria de massa por plasma acoplado indutivamente (ICPMS). A composição química do silício utilizado é mostrada na Tabela 1.

Tabela 1. Composição química inicial do silício utilizado (em ppm)

\begin{tabular}{|l|l|l|c|c|c|c|c|c|}
\hline Elemento & $\mathrm{B}$ & $\mathrm{P}$ & $\mathrm{Mn}$ & $\mathrm{Ca}$ & $\mathrm{Fe}$ & $\mathrm{Al}$ & $\mathrm{Cu}$ & $\mathrm{Ti}$ \\
\hline Teor & $10 \pm 1$ & $33 \pm 6$ & $45 \pm 8$ & $120 \pm 4$ & $2800 \pm 30$ & $234 \pm 96$ & $106 \pm 42$ & $75 \pm 25$ \\
\hline
\end{tabular}

\footnotetext{
* Contribuição técnica ao $69^{\circ}$ Congresso Anual da ABM - Internacional e ao 14ํㅡㄹ ENEMET - Encontro Nacional de Estudantes de Engenharia Metalúrgica, de Materiais e de Minas, 21 a 25 de julho de 2014, São Paulo, SP, Brasil.
} 


\section{RESULTADOS E DISCUSSÃO}

O teor de boro no silício foi reduzido de 10 para 0,5 ppm após $14400 \mathrm{~s}$ (4 horas) de ensaio. Após este tempo, a relação de gases foi alterada, com maior porcentagem de vapor de $\mathrm{H}_{2} \mathrm{O}$. Esta nova condição foi mantida durante $3600 \mathrm{~s}$ (1 hora), com redução no teor de boro de 0,5 para $0,09 \mathrm{ppm}$. A Figura 1 mostra uma curva com a variação no teor de boro com o tempo.

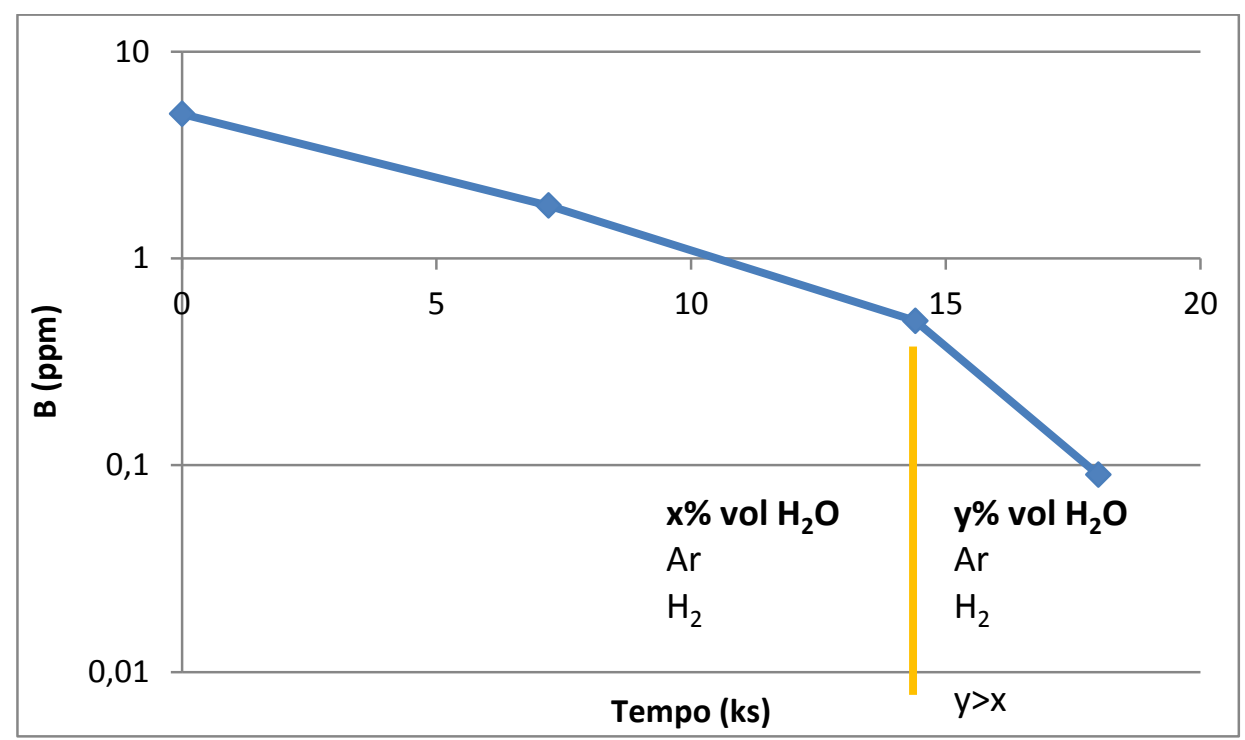

Figura 1. Curva de teor de boro em função do tempo, com aumento da concentração de vapor d'água após 14400 s (4 horas).

A taxa de remoção de boro parece estar relacionada com a quantidade de vapor de água na composição de gases em contato com o silício líquido. Isso pode ser observado no comportamento da curva após o aumento na porcentagem de vapor d'água. Estes resultados são consistentes com os obtidos por Nakamura et al. [3], mostrados na Figura 2, para temperatura entre 1823 e $1873 \mathrm{~K}\left(1550\right.$ e $\left.1600^{\circ} \mathrm{C}\right)$ e massa de $300 \mathrm{~kg}$ de silício.

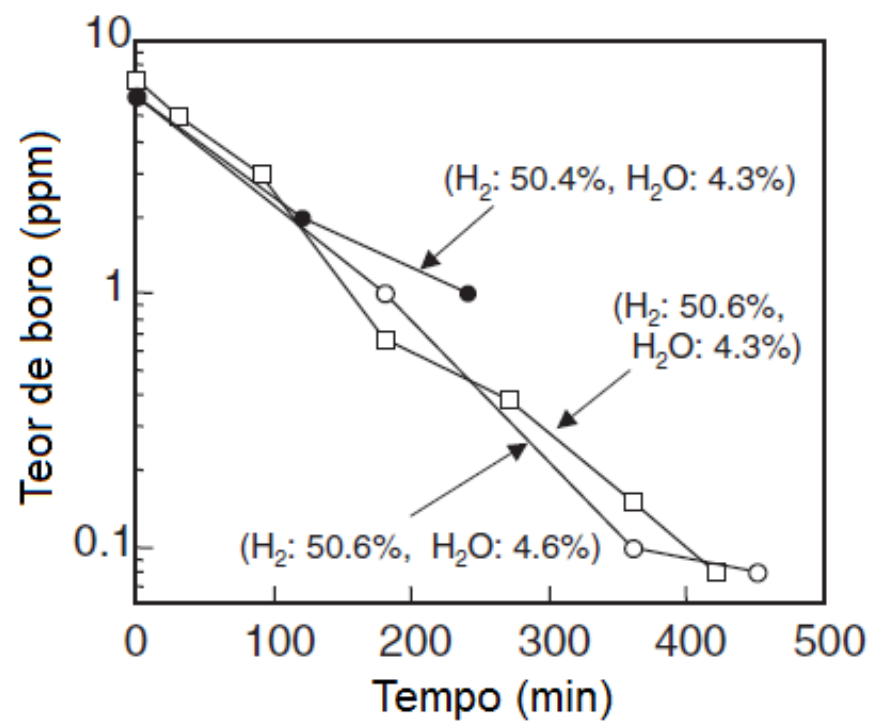

Figura 2. Resultados obtidos por Nakamura et al. [3] para diferentes concentrações de vapor d'água. $\mathrm{T}=1823-1873 \mathrm{~K}, \mathrm{~m}=300 \mathrm{~kg}$ de silício. Fonte: Adaptado de [3].

* Contribuição técnica ao $69^{\circ}$ Congresso Anual da ABM - Internacional e ao 14ํㅡㄹ ENEMET - Encontro Nacional de Estudantes de Engenharia Metalúrgica, de Materiais e de Minas, 21 a 25 de julho de 2014, São Paulo, SP, Brasil. 


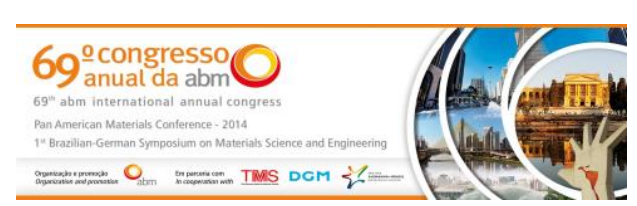

\section{CONCLUSÃo}

O processo de tratamento de silício a plasma sob atmosfera controlada contendo vapor d'água e hidrogênio é capaz de remover boro do silício eficientemente. A taxa de remoção de boro parece ter relação direta com a quantidade de $\mathrm{H}_{2} \mathrm{O}$ na atmosfera, elevando-se com o aumento desta.

\section{Agradecimentos}

Agradecemos a Companhia Ferroligas Minas Gerais (Minasligas) e ao Banco Nacional de Desenvolvimento Econômico e Social (BNDES).

\section{REFERÊNCIAS}

1 Coso G, Cañizo C, Sinke WC. The impact of silicon feedstock on the PV module cost. Solar Energy Materials \& Solar Cells. 2010; 94: 345-349.

2 Pizzini S. Towards solar grade silicon: Chalenges and benefits for low cost photovoltaics. Solar Energy Materials \& Solar Cells. 2010; 94: 1528-1533.

3 Nakamura N, Baba H, Sakaguchi Y, Kato Y. Boron Removal in Molten Silicon by a Steam-Added Plasma Melting Method. Materials Transactions. 2004; 45 (3): 858-864.

4 Safarian J, Tang K, Hildal K. Tranell G. Boron removal from silicon by humidified gases. Metallurgical and Materials Transactions E. 2014; 1E: 41-47.

\footnotetext{
* Contribuição técnica ao $69^{\circ}$ Congresso Anual da ABM - Internacional e ao 14ํㅡㄹ ENEMET - Encontro Nacional de Estudantes de Engenharia Metalúrgica, de Materiais e de Minas, 21 a 25 de julho de 2014, São Paulo, SP, Brasil.
} 